Revta brasil. Bot., São Paulo, V.24, n.1, p.109-121, mar. 2001

\title{
Morfo-anatomia e ontogênese do fruto e da semente de Tipuana tipu (Benth.) 0. Kuntze (Fabaceae: Faboideae)
}

\author{
MARCO ANTONIO GARCIA MARTINS ${ }^{1}$ e DENISE MARIA TROMBERT OLIVEIRA ${ }^{2,3}$
}

(recebido: 3 de maio de 2000; aceito: 11 de janeiro de 2001)

\begin{abstract}
Morphology, anatomy and ontogeny of the fruit and seed of Tipuana tipu (Benth.) O. Kuntze (Leguminosae: Faboideae)). Fruits and seeds of Tipuana tipu were morphologically and anatomically analyzed during development. The origin of the pericarpic wing was elucidated and the hypothesis of the occurrence of polyembriony mentioned in literature was verified. Slides were prepared according to the conventional techniques. The fruit of Tipuana tipu is a typical samara. Its wing originates from the lateral and terminal regions of the ovary and from the lateral of the style. The wing can be already traced in young ovaries of floral buds. Bitegmic ovules develop into testal seeds. The testa is not similar to those seen in typical legume integuments, frequently observed in species with indehiscent fruits. However, the hilum is typical of Faboideae. Seeds are exalbuminous and embryos present cotyledons and embryonic axis well developed. From 100 fruits analyzed mophologically, $61 \%$ were one-seeded, $34 \%$ two-seeded and only $5 \%$ three-seeded. From 144 seeds evaluated, only $2 \%$ were polyembryonic, showing two embryos per unit.
\end{abstract}

RESUMO - (Morfo-anatomia e ontogênese do fruto e semente de Tipuana tipu (Benth.) O. Kuntze (Fabaceae: Faboideae)). Frutos e sementes de Tipuana tipu foram analisados morfo-anatomicamente, durante seu desenvolvimento, objetivando descrever sua estrutura, esclarecer a origem da ala pericárpica e verificar a ocorrência de poliembrionia, hipótese levantada a partir de dados de literatura. Para tanto, preparou-se o laminário segundo técnicas convencionais e foram observados morfologicamente os embriões das sementes obtidas de 100 frutos. O fruto de T. tipu é uma sâmara, cuja ala se desenvolve a partir da região látero-apical do ovário e lateral do estilete, já estando delineada no ovário de botões florais jovens. As sementes, provenientes de óvulos bitegumentados, são unitegumentadas e testais. A testa não exibe a estrutura característica do tegumento das leguminosas, como é freqüente em espécies de frutos indeiscentes. O hilo, contudo, apresenta a típica estrutura das Faboideae. São sementes exalbuminosas, contendo embrião com eixo e cotilédones bem diferenciados. Dos 100 frutos analisados morfologicamente, $61 \%$ eram monospérmicos, 34\% dispérmicos e apenas 5\% trispérmicos. Do total de 144 sementes avaliadas, somente $2 \%$ eram poliembriônicas, com dois embriões por unidade.

Key words - Tipuana tipu, Fabaceae, fruit, seed, development

\section{Introdução}

Considerando-se que frutos e sementes exibem pequena plasticidade fenotípica, diversos autores têm se dedicado a ampliar as informações morfológicas e anatômicas referentes a esses órgãos, como subsídios para trabalhos taxonômicos, ecológicos e, especialmente, filogenéticos. Verificando-se a literatura pertinente, no entanto, nota-se que os frutos têm sido referidos apenas morfologicamente, muitas vezes sem precisão terminológica que permita a segura utilização dos dados. No que diz respeito às sementes, a carência de estudos descritivos e ontogenéticos da estrutura seminal torna muito difíceis as especulações a respeito das tendências evolutivas que afetaram esse órgão (Von Teichman \& Van Wyk 1991).

1. Aluno do curso de Agronomia, FCA, UNESP, Botucatu.

2. UNESP, Instituto de Biociências, Departamento de Botânica, Caixa Postal 510, 18618-000 Botucatu, SP, Brasil.

3. Autor para correspondência: doliveira@laser.com.br
A família Fabaceae compreende cerca de 650 gêneros e 18.000 espécies, agrupadas em três subfamílias (Gunn 1984). O elevado número de espécies engloba numerosos problemas taxonômicos e filogenéticos, que a análise de frutos e sementes pode ajudar a solucionar. A maior subfamília é Faboideae, que, segundo Polhill (1981a), compreende aproximadamente 440 gêneros e 12.000 espécies. Numerosas espécies de Faboideae concentram-se nas regiões tropicais, estando significativa parte das tribos Aeschynomeneae, Dalbergieae e Sophoreae centrada na América Latina (Raven \& Polhill 1981).

Dentre as Faboideae, a tribo Dalbergieae tem sido considerada um dos grupos ancestrais (Polhill et al. 1981), ocorrendo grande variação tipológica dos frutos. Observam-se frutos drupáceos, frutos flutuantes fibrosos e variadas formas de pericarpo alado, incluindo sâmaras típicas e frutos samaróides. Pelas observações já registradas na literatura e referidas por Polhill (1981b), essa tribo exibe grande variação no modo de formação da ala pericárpica, que pode ter as seguintes origens: expansão do pedúnculo ou do estilete, atenuação da margem do 
fruto, ou fusão e achatamento das valvas. Polhill (1981b) enfatiza que os frutos dessa tribo são sempre indeiscentes, formando cavidades seminais geralmente monospérmicas, delimitadas e protegidas pelo endocarpo lenhoso.

Outros estudos confirmaram as proposições supra-citadas para os frutos de Dalbergieae: Lima (1989-1990) citou somente frutos indeiscentes para a tribo, referindo sâmaras (incluindo aquelas de núcleo seminífero bem delimitado e os frutos samaróides) para 13 gêneros, ocorrendo ainda núculas e drupas. Oliveira (1997) estudou espécies de cinco diferentes gêneros de Dalbergieae, encontrando sâmaras em quatro deles e legume samaróide no quinto.

A morfologia da ala é tão importante em Dalbergieae que foi utilizada para distinguir três gêneros da tribo, cuja morfologia floral é praticamente idêntica: Platypodium, Pterocarpus e Tipuana (Lima 1989-1990).

Tipuana tipu (Benth.) O. Kuntze é uma espécie arbórea nativa da Bolívia e Argentina, introduzida em diversos países, onde é cultivada como ornamental (Polhill 1981a). No Brasil, esta espécie se tornou tão frequiente que é encontrada em formações secundárias, como componente de matas mesófilas semidecíduas (Pagano \& Leitão-Filho 1987). Poucos estudos estruturais foram resgatados com esta espécie, podendo ser destacado o estudo de Villari (1990-1991), que estudou alguns aspectos do desenvolvimento da antera e do óvulo de T. tipu, relatando características não referidas anteriormente para espécies de leguminosas. Como parte dessas variações, o autor citou o padrão de desenvolvimento da antera, a formação de vários megasporocitos que efetivamente passam pela divisão meiótica, com a conseqüente formação de mais de um megasporo por óvulo e, finalmente, a coexistência de três a quatro gametofitos maduros num mesmo óvulo.

Esse relato de Villari (1990-1991) indica tendência à poliembrionia múltipla (termo referido por Lakshmanan \& Ambegaokar 1984) ou pseudo-poliembrionia (termo utilizado por Eames 1977), pela formação de múltiplos embriões derivados da fecundação de diferentes oosferas, formadas em gametofitos diversos. Não se encontrou, contudo, referência direta à poliembrionia em $T$. tipu, talvez pela di- ficuldade técnica de se isolar as sementes maduras do pericarpo lenhoso.

Estudos ontogenéticos que não se detenham ao óvulo, mas à formação da semente, mostram-se necessários tanto para esclarecer a possibilidade de poliembrionia múltipla, quanto para confirmar algumas das observações de Villari (1990-1991).

Com base nas considerações precedentes, os frutos e sementes de T. tipu foram analisados morfoanatômica e ontogeneticamente neste trabalho, objetivando descrever os frutos e sementes, nas diversas fases de seu desenvolvimento, esclarecer a origem da ala pericárpica e verificar a ocorrência de poliembrionia.

\section{Material e métodos}

O material botânico utilizado no presente trabalho constou de primórdios e botões florais, flores em antese e pós-antese, frutos jovens em diversas fases de desenvolvimento e frutos maduros, coletados em indivíduos cultivados na UNESP, Campus de Botucatu. Pequenos ramos de Tipuana tipu (Benth.) O. Kuntze foram coletados, herborizados e depositados no Herbário "Irina D. Gemtchujnikov" (BOTU) do Departamento de Botânica, UNESP, Campus de Botucatu, como documento taxonômico, registrados sob o número 22935 .

Para se verificar a ocorrência de poliembrionia, 100 frutos em fase final de amadurecimento, coletados de cinco matrizes, tiveram suas sementes isoladas, sendo as mesmas analisadas sob microscópio estereoscópio em busca de embriões extra-numerários. Todos os embriões observados foram medidos com auxílio de paquímetro (comprimento, largura e espessura), obtendo-se também o peso da matéria fresca em balança analítica. Foram calculados a média, o desvio padrão e a amplitude de variação dos dados, bem como a frequência de sementes poliembriônicas.

Os estudos morfo-anatômicos foram realizados em material fresco ou em material fixado em FAA a 50\% (Johansen 1940) ou na solução de Karnovsky (Karnovsky 1965). Ambos os materiais foram conservados em álcool etílico a 70\% (Jensen 1962).

Para elaboração de laminário permanente, após desidratação em série etílica, o material foi incluído em glicol-metacrilato e microtomado com cerca de $8 \mu \mathrm{m}$ de espessura, obtendo-se séries longitudinais e transversais. As seções obtidas foram coradas com Azul de Toluidina (O'Brien et al. 1964) e montadas em Permount.

Foram confeccionadas também lâminas semi-permanentes, utilizando-se cortes transversais e longitudinais feitos a mão livre, com auxílio de lâmina de barbear. Estes foram corados com Safranina e Azul de Astra, sendo montados em gelatina glicerinada.

Alguns cortes foram preparados para a realização de testes visando à detecção de algumas substâncias. Foram utilizados os seguintes corantes e reagentes: Vermelho de Rutênio, para identificar polissacarídeos diversos e pectinas (Jensen 1962); floroglucinol em meio ácido, para evidenciar paredes lignificadas (Sass 1951); Sudan IV, para a localização de substâncias lipofílicas; lugol, para a localização de amido; cloreto férrico, para verificar 
a ocorrência de compostos fenólicos, especialmente taninos (Johansen 1940).

Frutos completamente expandidos foram diafanizados pela técnica proposta por Fuchs (1963), sendo as alas montadas em gelatina glicerinada, para observação de sua venação.

Os resultados foram ilustrados por meio de fotomicrografias obtidas em fotomicroscópio Zeiss, ou desenhos em detalhe feitos em microscópio de projeção Zeiss, acrescentando-se escalas nas condições ópticas adequadas. Aspectos morfológicos foram registrados com desenhos elaborados em câmara clara acoplada a estereomicroscópio Zeiss.

\section{Resultados}

Análise morfométrica - Os frutos de Tipuana tipu apresentaram em média 1,44 $\pm 0,59$ sementes, sendo $61 \%$ monospérmicos, $34 \%$ dispérmicos e apenas $5 \%$ trispérmicos. Destas sementes, apenas $2 \%$ exibiram poliembrionia, observando-se dois embriões por unidade. Essas sementes poliembriônicas foram coletadas em diferentes plantas matrizes. Os resultados da análise morfométrica dos embriões são mostrados na tabela 1 .

Análise morfo-anatômica - Os resultados da análise morfo-anatômica estão agrupados em quatro estádios de desenvolvimento, separados de acordo com o grau de diferenciação: estádio I - ovário indiferenciado; estádio II - divisões celulares no pericarpo e semente; estádio III - alongamento celular no pericarpo e semente; estádio IV - lignificação do estrato esclerenquimático.

Estádio I (figuras 1-7, 13) - O estádio inicial de desenvolvimento dos frutos e sementes é representado pelo ovário dos botões florais jovens (figura 1). O ovário apresenta-se elevado por uma pequena estipe (figura 1) e, em sua região mediana, tem secção transversal oval com uma projeção que denota a formação da ala (figura 4), a qual fica mais pronunciada em direção ao estilete (figura 7), que é

Tabela 1. Média, desvio-padrão e amplitude de variação das dimensões e peso da matéria fresca dos embriões de $T$. tipu, isolados das sementes encontradas em 100 frutos $(n=147)$.

\begin{tabular}{lccc}
\hline Variável & Média & $\begin{array}{c}\text { Desvio } \\
\text { padrão }\end{array}$ & $\begin{array}{c}\text { Amplitude } \\
\text { de variação }\end{array}$ \\
\hline Comprimento $(\mathrm{cm})$ & 0,79 & 0,09 & $0,53-1,06$ \\
Largura $(\mathrm{cm})$ & 0,32 & 0,05 & $0,22-0,44$ \\
Espessura $(\mathrm{cm})$ & 0,12 & 0,03 & $0,05-0,19$ \\
Peso da matéria fresca $(\mathrm{mg})$ & 17,14 & 0,01 & $3,30-39,70$ \\
\hline
\end{tabular}

terminal. Na base (figura 5), essa projeção é menos evidente.

O ovário geralmente contém quatro óvulos em formação, dispostos em uma única fileira, com placentação sutural (figura 1).

A epiderme externa do ovário é unisseriada e composta por células cubóides (figura 4), recoberta por cutícula delgada. Observam-se tricomas diferenciados unicelulares e, em algumas regiões, o início da formação de tricomas secretores, pluricelulares e plurisseriados.

O mesofilo ovariano compõe-se de células de parênquima fundamental (figura 4), ocorrendo alguns idioblastos taniníferos, dispostos na periferia dos feixes vasculares, com maior concentração junto dos feixes ventrais. São observados três feixes vasculares colaterais já diferenciados, um voltado para a face dorsal e dois para a face ventral do ovário, imersos no mesofilo (figura 4). Ocorrem alguns cordões procambiais, imersos ao longo de toda lateral do ovário, raramente acompanhados por idioblastos taniníferos (figuras 4, 5, 7, 13).

A epiderme interna também é unisseriada, composta por células achatadas periclinalmente (figuras $4,6,13)$, de tamanho similar às que constituem a epiderme externa, sendo revestida por cutícula delgada, além de ser desprovida de tricomas em toda sua extensão. Na região placentária as células possuem citoplasma mais denso (figuras 4,6), formando uma protuberância na parede periclinal voltada para a cavidade seminal.

Os óvulos são bitegumentados (figuras 2, 3) e campilótropos (figura 3). O tegumento externo compõe-se de duas a quatro camadas de células indiferenciadas, recobertas por cutícula delgada. O tegumento interno é reduzido e composto por uma a duas camadas de células, atingindo apenas um terço do óvulo; é recoberto por cutícula delgada (figura 3).

O óvulo é crassinucelado, sendo a célula-mãe do megasporo diferenciada a duas camadas da superfície (figura 3).

Estádio II (figuras 8-12, 13-18) - Abrange o ovário do botão floral pré-antese, a flor em antese e a fase imediatamente pós-antese. Ao final desta fase, observa-se a abscisão da corola e do androceu. Neste estádio, predomina a atividade meristemática, ocorrendo divisões celulares em todo o ovário. 

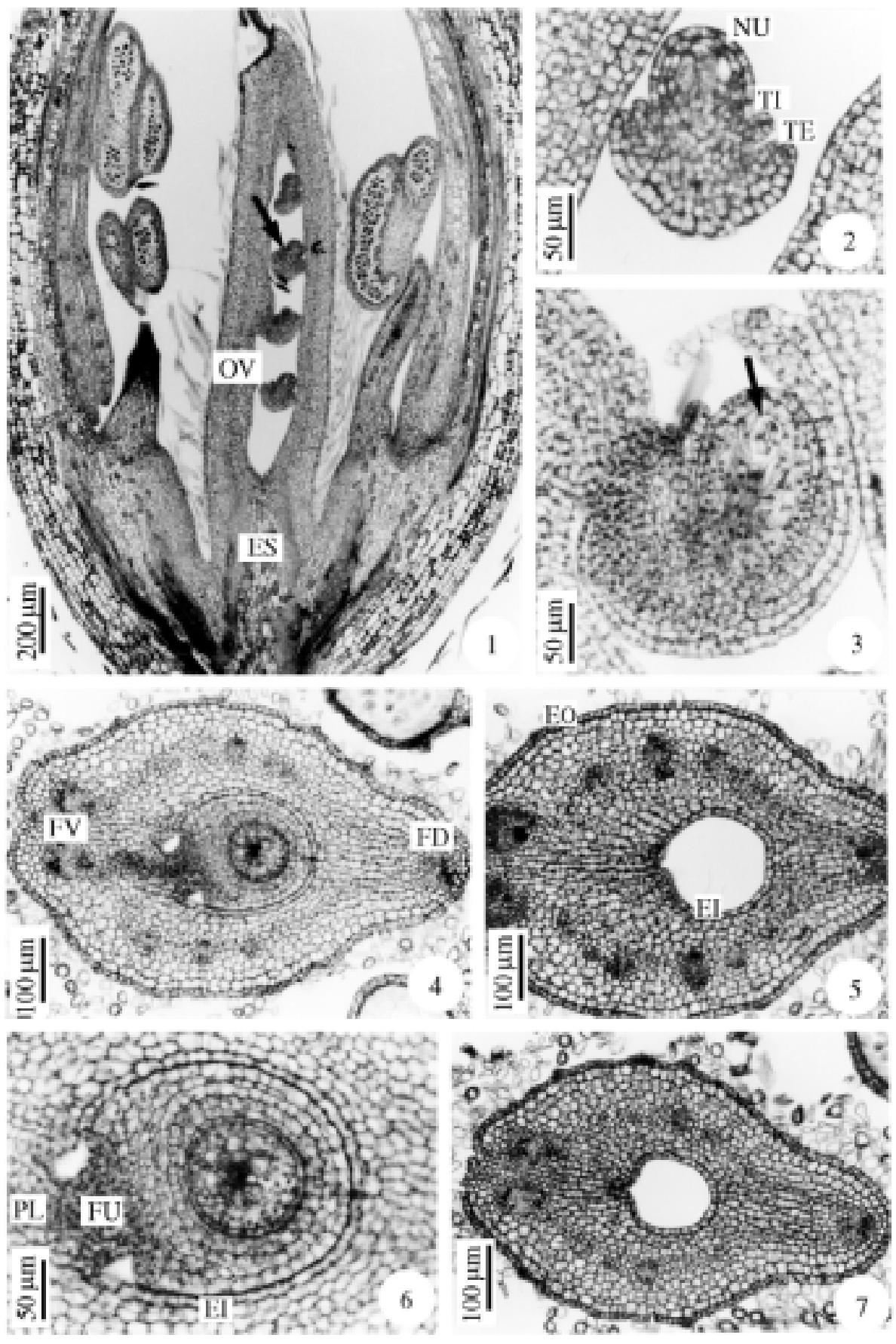

Figuras 1-7. Estádio I. 1. Botão floral jovem em corte longitudinal, mostrando óvulos em formação (seta). 2. Aspecto geral do óvulo do botão floral jovem, mostrando a ontogênese dos tegumentos. 3. Detalhe do corte longitudinal do óvulo do botão floral ainda jovem, mostrando os tegumentos, a campilotropia ovular e a diferenciação da célula-mãe do megasporo (seta). 4-7. cortes transversais: 4. Vista geral do ovário do botão floral jovem, mostrando um óvulo. 5. Vista geral da base do ovário. 6. Detalhe do óvulo do botão floral jovem, mostrando maior densidade do citoplasma das células da região placentária e funicular. 7. Vista geral do ápice do ovário. (EO: epiderme externa do ovário, EI: epiderme interna do ovário, ES: estipe, FD: feixe dorsal do carpelo, FV: feixe ventral do carpelo, FU: funículo, NU: nucelo, OV: ovário, PL: placenta, TE: tegumento externo, TI: tegumento interno). 
Revta brasil. Bot., São Paulo, V.24, n.1, p.109-121, mar. 2001

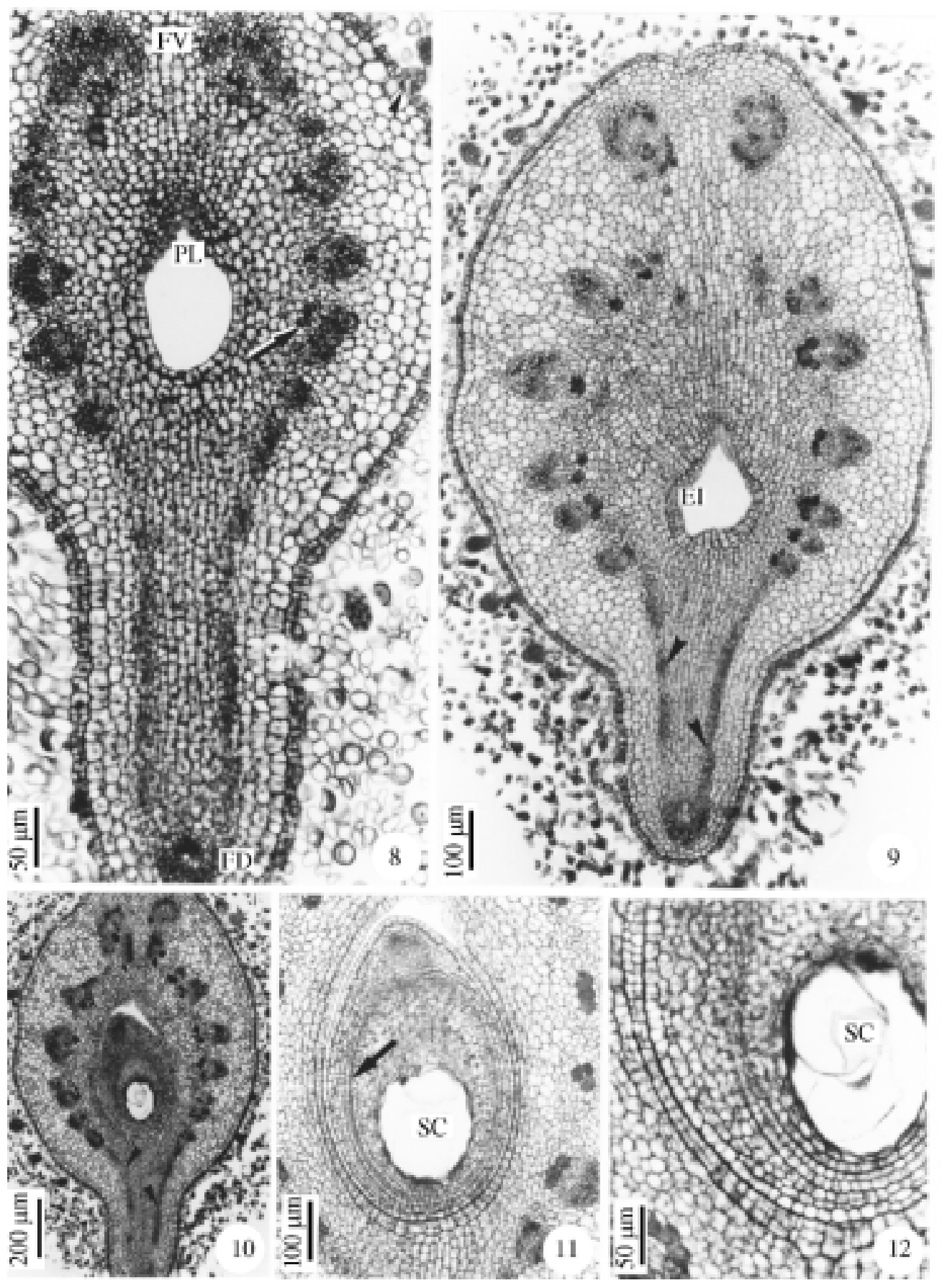

Figuras 8-12. Estádio II, cortes transversais. 8. Vista geral do ovário do botão floral em pré-antese, mostrando alongamento da região dorsal, formação de tricomas secretores (ponta de seta), diferenciação dos feixes vasculares laterais com idioblastos taniníferos (seta). 9. Vista geral do ovário da flor pós-antese, mostrando ramificações procambiais (pontas de setas) e feixes laterais diferenciados, com idioblastos taniníferos. 10. Vista geral do ovário da flor pós-antese, mostrando óvulo com saco embrionário diferenciado (pontas de seta indicam cordões procambiais). 11. Detalhe do óvulo da flor pós-antese, mostrando compressão do tegumento interno (seta). 12. Detalhe do óvulo da flor pós-antese. (EI: epiderme interna do ovário, FD: feixe dorsal do carpelo, FV: feixe ventral do carpelo, PL: placenta, SC: saco embrionário, TE: tegumento externo). 

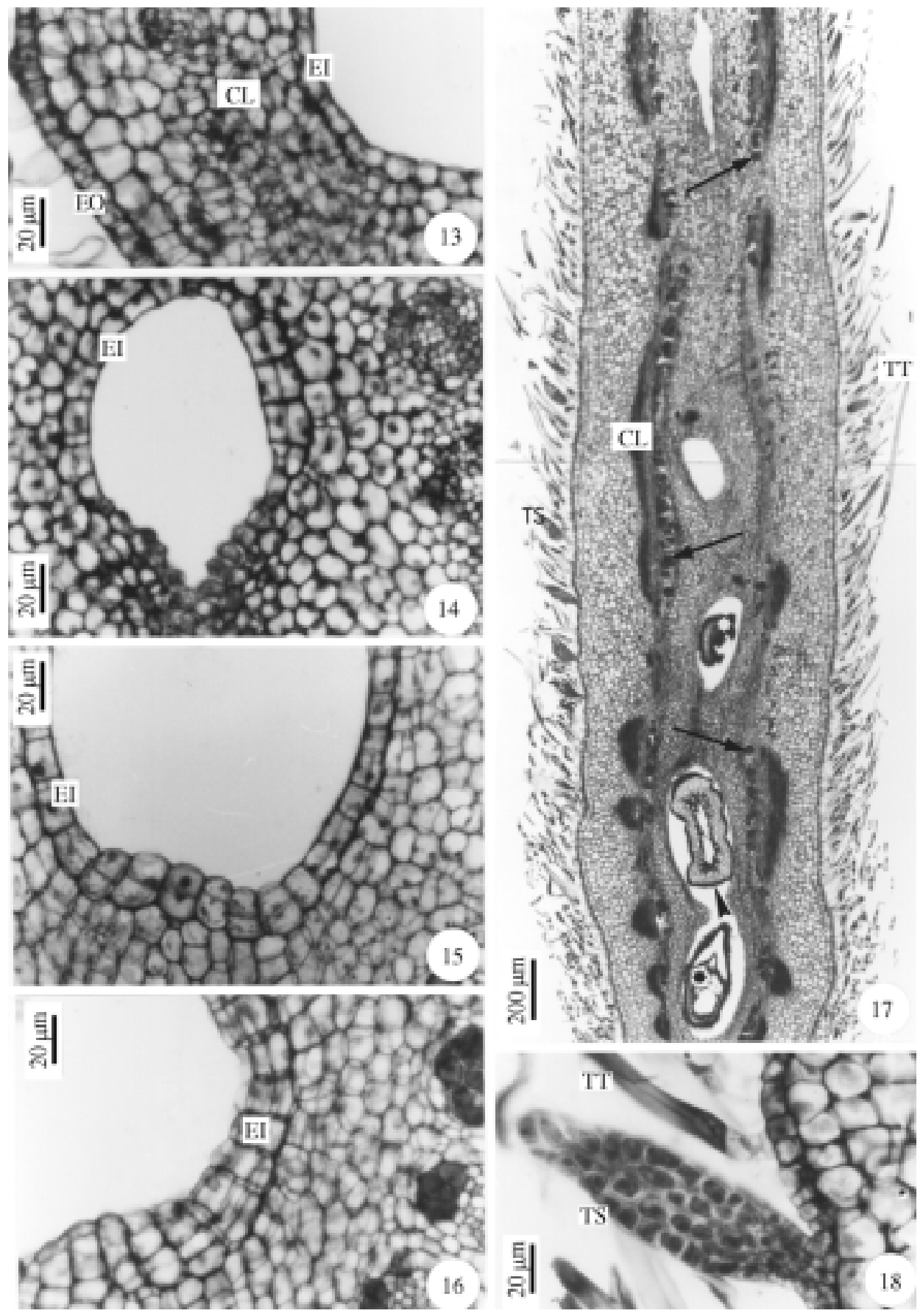

Figuras 13-18. Estádios I e II. 13-16. cortes transversais; 17-18. cortes longitudinais. 13. Detalhe do ovário do botão floral jovem, mostrando a parede ovariana. 14-15. Detalhe do ovário da flor em antese, mostrando divisões na epiderme interna. 16. Detalhe do ovário da flor pós-antese, mostrando a epiderme interna multisseriada. 17. Aspecto geral do fruto, mostrando quatro cavidades seminais isoladas por tabiques transversais, com uma semente em desenvolvimento (ponta de seta) e outras abortadas (*). Notar idioblastos secretores indicados pelas setas. 18. Detalhe da epiderme externa (exocarpo jovem), com tricomas tectores e secretores. (EO: epiderme externa do ovário, EI: epiderme interna do ovário, CL: cordão procambial que diferenciará feixe lateral, TS: tricoma secretor, TT: tricoma tector). 
O ovário mantém formato similar ao da fase anterior, porém com grande alongamento na região dorsal (figura 8).

A epiderme externa do ovário mantém-se unisseriada, com células de formato semelhante ao da fase anterior. Na região dorsal, porém, as células epidérmicas externas apresentam-se alongadas e com intensas divisões anticlinais. Divisões periclinais e anticlinais ocorrem somente onde estão se diferenciando tricomas secretores (figuras 8, 17, 18).

O mesofilo é composto por tecido fundamental em divisão, ocorrendo, na periferia do ovário, células bem vacuoladas e, dentro do cilindro vascular, células de tamanho reduzido e citoplasma denso, com intensa atividade meristemática (figuras 8, 1416). Há diferenciação dos feixes vasculares laterais do ovário, agora acompanhados por grandes idioblastos taniníferos (figuras 8-10, 16-17). Na região dorsal, longas ramificações procambiais são observadas (figuras 8-10).

A epiderme interna do ovário apresenta divisões periclinais em toda a sua extensão, constituindo a princípio duas camadas (figuras 8, 14, 15) e, ao final desse estádio, muitas camadas de células (figuras 9, 16). A placenta não exibe alterações (figura 8).

No óvulo, o tegumento externo não mostrou grandes alterações, ocorrendo apenas divisões anticlinais que acomodam o seu crescimento (figuras 11, 12). O tegumento interno inicia este estágio como descrito anteriormente e, ao final, encontra-se ligeiramente comprimido (figura 11). O nucelo está sendo consumido enquanto o saco embrionário se desenvolve. Ocorre a fecundação e inicia-se o desenvolvimento do endosperma, que é nuclear.

Nesta fase, muitos dos óvulos são abortados (figura 17), desenvolvendo-se apenas uma semente na maioria dos casos.

Estádio III (figuras 19-28) - O fruto jovem no estádio III apresenta alongamento celular em todas as regiões do pericarpo, resultando em aumento do tamanho. Nesta fase, o fruto já é bem distinto como uma sâmara, onde o núcleo seminífero tem grande destaque da ampla ala dorso-apical. Delimitando a face ventral da ala, na região apical do ovário, encontra-se o estilete. Ao final desta terceira fase, o fruto exibe seu tamanho final e intensa coloração verde.

Nas sementes, o alongamento celular também é muito nítido, obliterando as cavidades seminais. São sementes campilótropas, com hilo ovalado e conspícuo, rodeado pelo rim hilar (figuras 25-26). A testa tem coloração esbranquiçada e não é multiplicativa, mas acompanha o crescimento da amêndoa (figuras 19-24). Sua epiderme externa é taninífera (figuras 23-24), fato que foi verificado no teste com cloreto férrico. $\mathrm{O}$ endosperma tem seu maior desenvolvimento no início deste estádio, havendo celularização centrípeta (figuras 19-21). Ao final do estádio III, o embrião consumiu todo o endosperma e a semente é exalbuminosa.

As maiores modificações seminais neste estádio aparecem no embrião, que inicialmente é globular (figuras 19, 23), passa a cordiforme (figura 24) e atinge sua morfologia característica, com dois cotilédones foliáceos, discretamente dorsiventrais e de reserva amilácea, unidos ao eixo hipocótilo-radícula proporcionalmente longo e curvo (figuras 27-28). $\mathrm{Na}$ figura 28, encontram-se ilustrados dois embriões provenientes de uma semente poliembriônica de $T$. tipu, destacando-se a diferença de tamanho entre eles.

Estádio IV (figuras 29-34) - Neste estádio, dá-se o amadurecimento e desidratação do fruto e da semente, observados externamente pelo amarelecimento do pericarpo. Também as sementes mudam de coloração, passando de esbranquiçadas a marrom-acastanhadas.

No fruto, o núcleo seminífero torna-se pétreo e a ala muito fibrosa, por causa da intensa vascularização (figura 29). O exocarpo se mantém unisseriado, recoberto por nítida cutícula (figura 32).

O mesocarpo externo apresenta reforços subepidérmicos de colênquima, nas regiões ventral e dorsal (figuras 30, 32), intercalados com grande extensão de parênquima fundamental nas laterais (figura 30), onde se verificam algumas gotículas de lipídeos e não há reserva de amido. $\mathrm{O}$ mesocarpo interno apresenta numerosos feixes vasculares colaterais, acompanhados por muitas fibras e delimitados por cristais prismáticos de pequeno tamanho (figuras 30, 31).

No endocarpo, também se distinguem duas regiões: uma camada maciça de fibras, dispostas em direções variadas, constituem o endocarpo externo, ou seja, compõem o estrato esclerenquimático deste fruto (figuras 30, 34). Essa camada fibrosa é mais espessa na região do núcleo seminífero, tornando-se 

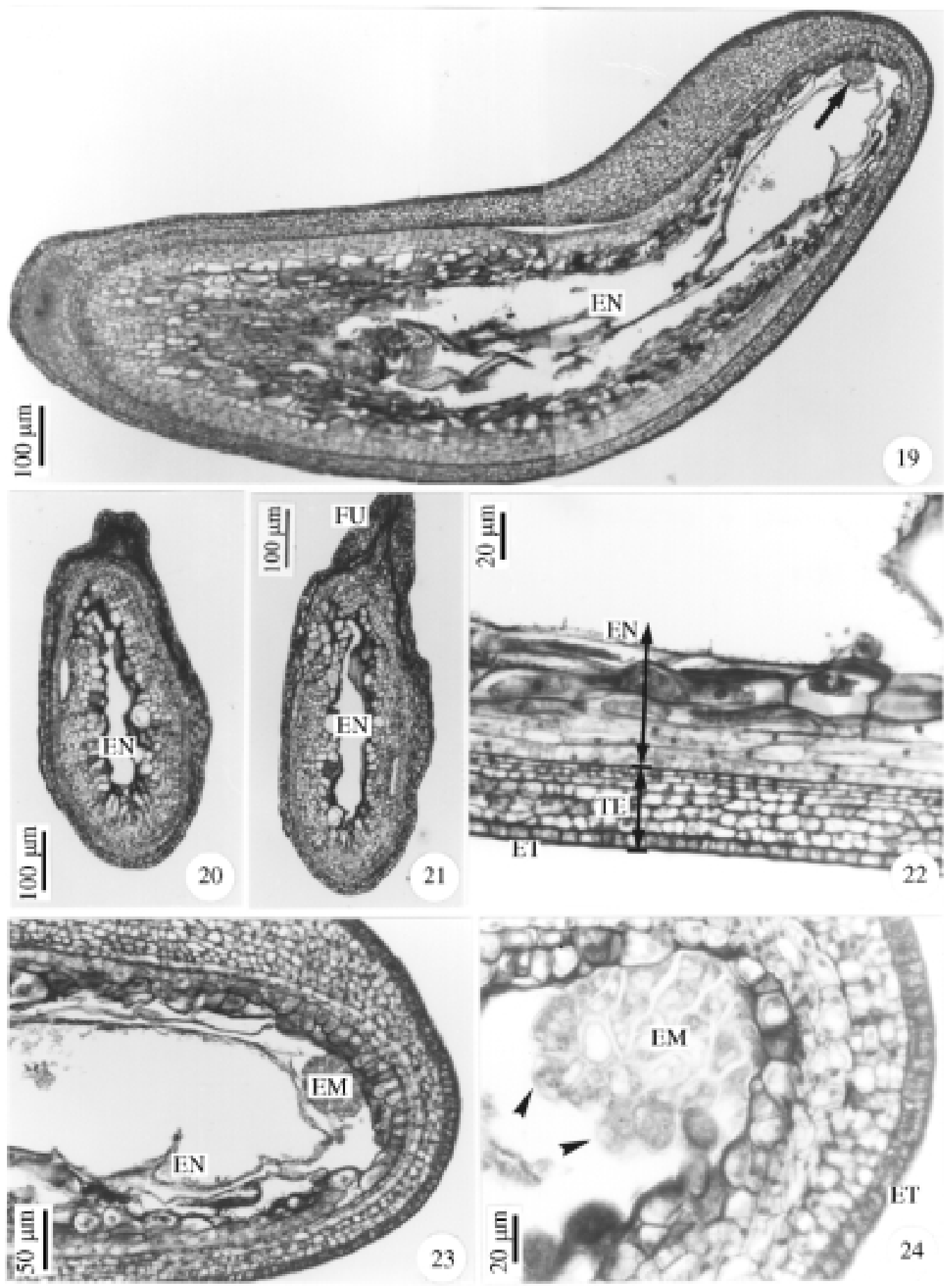

Figuras 19-24. Semente no estádio III. Cortes longitudinais, exceto 20 e 21, que são transversais. 19-21. Aspecto geral da semente, mostrando a testa, o endosperma nuclear, celularizado em parte, e o embrião jovem (seta). 22. Detalhe do tegumento e endosperma. 23-24. Detalhes de sementes, evidenciando a testa com epiderme externa taninífera, endosperma e embrião globular na primeira e cordiforme na segunda (pontas de seta indicam os primórdios dos cotilédones). (EM: embrião, EN: endosperma, ET: epiderme externa da testa, FU: funículo, TE: testa). 


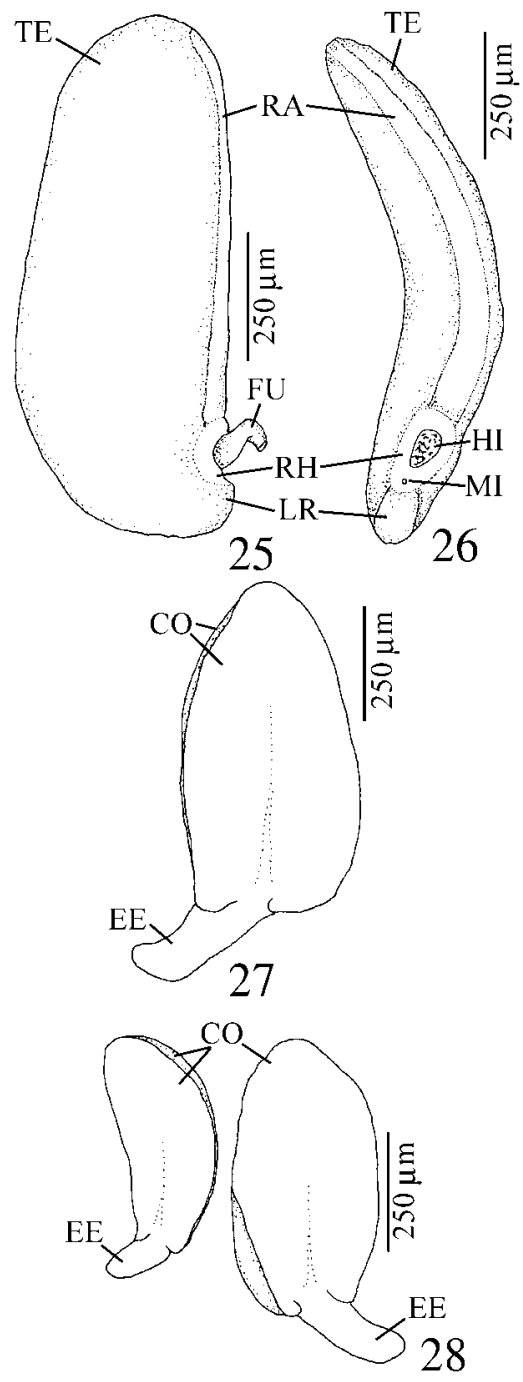

Figuras 25-28. Semente no final do estádio III. 25. Semente isolada do pericarpo em vista lateral, mostrando o funículo e o lobo radicular. 26. Semente isolada em vista frontal, mostrando o hilo, o rim hilar, a micrópila e a rafe. 27. Embrião isolado da semente, mostrando os cotilédones e o eixo embrionário curvo. 28. Aspecto geral de dois embriões isolados de uma semente poliembriônica. (CO: cotilédone, EE: eixo embrionário, FU: funículo, HI: hilo, LR: lobo radicular, MI: micrópila, RA: rafe, RH: rim hilar, TE: testa).

mais delgada e interrompida na ala (figura 30), sempre margeada por grande número de cristais prismáticos de oxalato de cálcio (figura 34).

O endocarpo interno está constituído pelo parênquima aerífero, composto por células bracifor- mes em vista frontal (figura 33), que apresentam fraca reação ao florogucinol $+\mathrm{HCl}$. Este tecido reveste toda a cavidade seminal (figura 30 ), constituindo o "seed cushion". Na ala, o parênquima aerífero das duas laterais se reúne na região mediana (figura 30), ocupando grande extensão. Este tecido, ao final da desidratação do pericarpo, aparece comprimido pelo estrato esclerenquimático.

A semente exibe a mesma estrutura do estádio anterior, passando apenas pela desidratação do embrião e testa, esta escurecida pela concentração dos taninos.

\section{Discussão}

Os dados morfométricos de frutos e sementes são utilizados por diversos autores (Boelcke 1946, Bravato 1974, Gunn 1984, Lima 1985, Roosmalen 1985, Sanchotene 1985) para caracterização de várias espécies. Segundo Oliveira \& Beltrati (1994), embora de valor taxonômico questionável, os dados morfométricos têm indiscutível valor ecológico, auxiliando na determinação da variabilidade da espécie, bem como no estudo do tipo de dispersão e dos agentes dispersores.

Quanto à questão da poliembrionia, o registro de apenas $2 \%$ de sementes poliembriônicas não permite que se utilize este aspecto para caracterizar sementes de T. tipu. Também não foi possível observar a formação de mais de um gametofito maduro num mesmo óvulo, descrita por Villari (1990-1991) para esta espécie. Como o autor não registrou quantas matrizes utilizou para coleta de material, é possível que seu material tenha sido coletado de uma ou poucas árvores, em que a produção de vários megasporos que desenvolvam diversos gametofitos num mesmo óvulo seja mais frequente que o normal. Utilizando-se cinco matrizes para coletas neste trabalho, não foi confirmado esse relato.

É interessante notar que é grande a variação observada nas dimensões dos embriões de T. tipu. Este fato é freqüente em espécies com sementes poliembriônicas, já que o tamanho total da semente sofre pequena variação, quer comporte embrião único, quer abrigue poliembriões. Mesmo entre estes últimos, há grande variação de tamanho, geralmente prevalecendo um deles, como visto na figura 28 . 


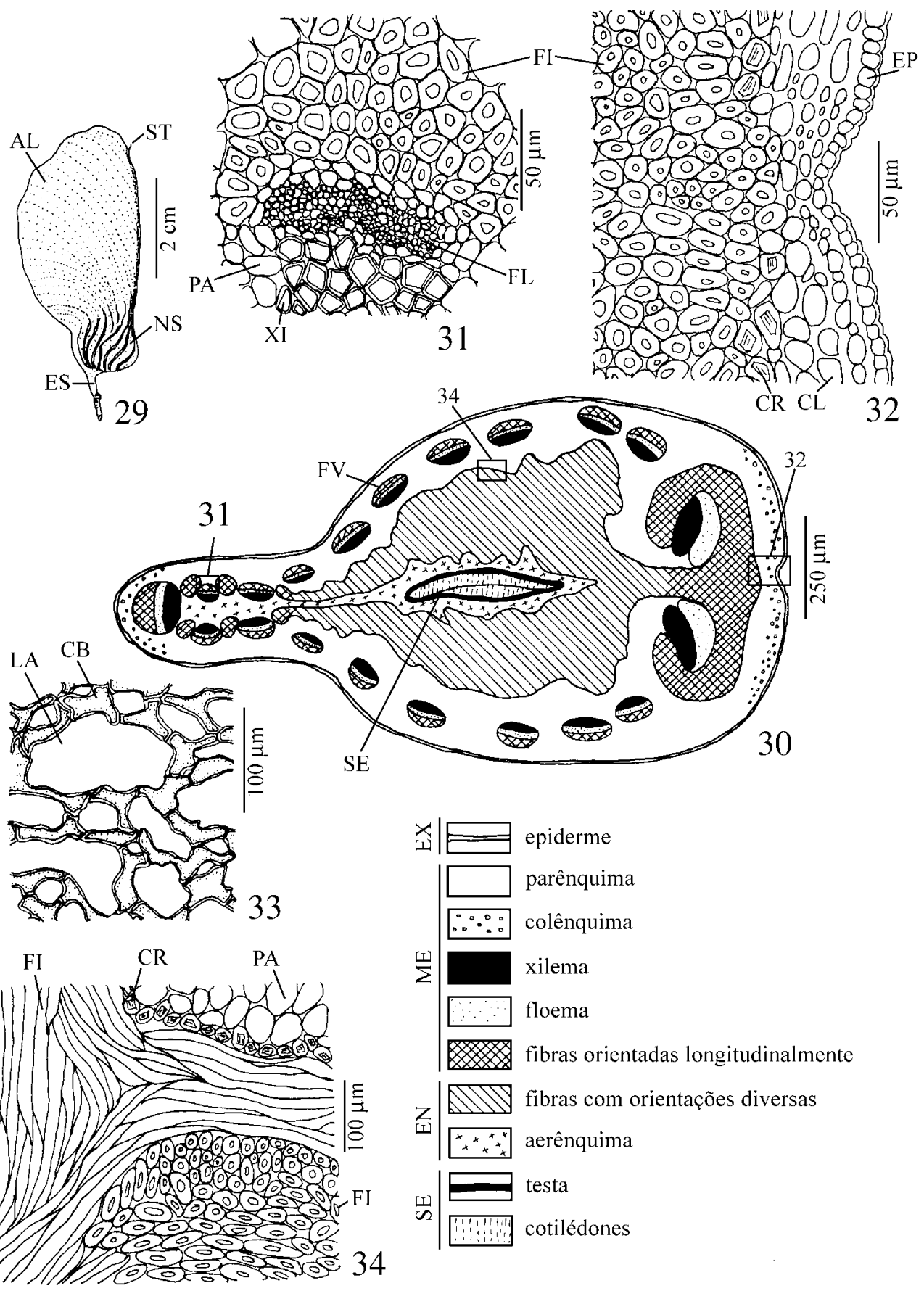

Figuras 29-34. Estádio IV. 29. Aspecto geral do fruto maduro. 30. Diagrama do corte transversal mediano do núcleo seminífero com semente em seu interior. 31. Detalhe do feixe vascular do mesocarpo interno, na posição indicada na figura 30. 32. Detalhe do exocarpo, mesocarpo externo e parte do mesocarpo interno, na região ventral do fruto, na posição assinalada na figura 30.33 . Detalhe do aerênquima do endocarpo interno, em seção longitudinal da ala, mostrando as células braciformes. 34. Detalhe do endocarpo externo, mostrando as fibras com orientações variadas, acompanhadas externamente por séries de cristais. (AL: ala, CB: célula braciforme, CL: colênquima, CR: cristal, EN: endocarpo, EP: epiderme, ES: estipe, EX: exocarpo, FI: fibras, FL: floema, FV: feixe vascular, LA: lacuna, ME: mesocarpo, NS: núcleo seminífero, PA: parênquima, SE: semente, ST: extremidade do estilete, XI: xilema). 
O fruto de T. tipu é tradicionalmente classificado como sâmara (Vidal \& Vidal 1992, Spjut 1994, Barroso et al. 1999). Alguns autores como Dudik (1981), no entanto, propõem a utilização do termo legume para todos os frutos de leguminosas, independente de sua morfologia. Considerando a grande variabilidade carpológica das Faboideae, optou-se neste trabalho por manter o termo sâmara, que explicita a estrutura observada na espécie em estudo.

Polhill (1981b) enfatizou que os frutos das espécies de Dalbergieae são sempre indeiscentes, formando cavidades seminais em geral monospérmicas, delimitadas e protegidas pelo endocarpo lenhoso. A monospermia foi considerada constante nos frutos secos indeiscentes e nas drupas por Van der Pijl (1982), que correlacionou especialmente a estrutura pericárpica aos mecanismos de deiscência da espécie. Já Barroso et al. (1999) consideraram a sâmara uma especialização do legume e afirmaram que, nas leguminosas, podem ser encontrados frutos desse tipo com duas ou três sementes, separadas por tabiques transversais. Sâmaras de tal estrutura foram observadas em T. tipu e descritas neste trabalho. $\mathrm{O}$ caráter monospérmico prevaleceu em $61 \%$ dos frutos analisados aqui, contra $34 \%$ de frutos dispérmicos e apenas $5 \%$ trispérmicos. Desta forma, considera-se que a afirmativa supra-referida de Van der Pijl (1982) não é totalmente adequada, podendo-se dizer que a monospermia é uma tendência nos frutos secos indeiscentes, porém não é uma constância.

Embora se registre grande variação entre frutos secos indeiscentes, é de conhecimento geral que, dentro dos gêneros, a morfologia do fruto é caráter pouco variável. Burnham (1995) estudou fósseis de T. ecuatoriana datados do Mioceno, descrevendo seus frutos alados de modo muito semelhante aos da espécie atual. Segundo o referido autor, as características de vascularização da ala são muito importantes para a identificação das espécies no registro fóssil.

Anatomicamente, as características do pericarpo de $T$. tipu explicam sua indeiscência. Antes da fase de maturação (até o estádio III), prevalecem células de parede delgadas e quando espessadas, sem grande lignificação. Na maturidade (estádio IV), contudo, a grande lignificação do estrato esclerenquimático e a disposição irregular de suas células impedem a deiscência.
A estrutura desse pericarpo enquadra-se, com pequena variação, no tipo Coronilla proposto por Fahn \& Zohary (1955), descrito como fruto que apresenta as fibras do estrato esclerenquimático paralelas às valvas em sua região mediana, com blocos transversais próximos aos feixes vasculares, que estão também acompanhados por fibras. Segundo esses autores, fibras reunidas em uma só camada, com orientações variáveis ao longo da valva, conduzem à indeiscência.

Nas Faboideae, prevalecem espécies de pericarpos com uma só camada de fibras (Fahn \& Zohary 1955). Segundo os autores citados, o pericarpo de $T$. tipu apresenta estrutura intermediária entre os frutos mais primitivos (com duas camadas no estrato esclerenquimático) e os derivados (aqueles sem estrato esclerenquimático).

Algumas características citadas por Dudik (1981) refletem o elevado grau de especialização dos frutos e sementes de T. tipu: frutos com poucas sementes, tendendo a monospérmicos; fruto indeiscente, septado transversalmente; semente campilótropa, exalbuminosa, sem alas ou arilos.

A descrição do desenvolvimento dos frutos e sementes utilizando períodos de crescimento foi inicialmente feita por pesquisadores que analisaram pericarpos carnosos (Lilleland 1930, 1932, 1933, Tukey \& Young 1939, Nitsch 1953). Esses autores reconheceram três ciclos de crescimento: o primeiro, em que ocorre rápido aumento no tamanho do fruto e tegumentos seminais; o segundo, onde o embrião se diferencia, embora a velocidade de crescimento do fruto diminua sensivelmente; e o terceiro, que é caracterizado pela paralisação do desenvolvimento do embrião e retomada de um ativo alongamento no fruto.

Como tal procedimento mostrou-se eficiente, frutos secos também passaram a ser descritos dessa forma, com as devidas adaptações, especialmente porque, nesses pericarpos, o crescimento não é retomado após o desenvolvimento seminal (Bisson \& Jones 1932, Nitsch 1953, Souza 1984, Oliveira \& Beltrati 1993).

O pericarpo de T. tipu apresentou o desenvolvimento característico dos frutos secos, partindo da estrutura ovariana (estádio I), passando pelo ciclo de crescimento por divisão celular (estádio II), seguido da fase de alongamento celular (estádio III) e, final- 
mente, apresentando a lignificação do estrato esclerenquimático pericárpico (estádio IV).

Quanto ao desenvolvimento da semente, Souza (1984) e Oliveira \& Beltrati (1993) relataram dois processos possíveis: o primeiro trabalho se refere ao desenvolvimento da semente paralelamente ao do pericarpo (fato também verificado em $T$. tipu) e o segundo relata a diferenciação seminal somente após a lignificação pericárpica. Segundo Roth (1977), nos frutos que desenvolvem prematuramente um tecido multisseriado que reveste a cavidade seminal ("seed cushion"), a pressão do pericarpo em desenvolvimento sobre a semente é amortecida, propiciando seu desenvolvimento paralelo. Do contrário, quando os tecidos esclerenquimáticos do meso e/ou endocarpo e o parênquima que reveste a cavidade seminal se formam em fase adiantada do amadurecimento (estádio IV), a semente só se diferencia após essa fase.

Um fato que merece atenção em $T$. tipu é a redução do tegumento interno, no início da diferenciação seminal. Eames \& MacDaniels (1953) generalizaram que ocorre absorção completa do tegumento interno e do nucelo nas sementes de leguminosas.

Também a presença de inúmeros idioblastos taniníferos no pericarpo e na epiderme externa da testa é fato que merece destaque. Numerosos trabalhos relacionam a ocorrência dos compostos fenólicos à proteção do embrião, especialmente pela resistência que conferem ao ataque de patógenos (Suárez \& Engleman 1980). Quando o fruto é deiscente, os taninos se concentram principalmente nos tegumentos, acumulando-se também em grandes quantidades nos frutos de pericarpo indeiscente. É sabido que, nos frutos das Dalbergieae, é abundante a ocorrência de compostos fenólicos, em especial calconas, isoflavonóides, neoflavonóides e quinonas que, contudo, têm sido pouco estudados (Polhill 1981b).

As sementes de Fabaceae são, de modo geral, consideradas impermeáveis, sendo a escarificação um requisito para que a embebição e a germinação possam ocorrer (Corner 1951, Quinlivan 1971). Os seguintes fatores têm sido considerados como causas da impermeabilidade em Fabaceae: barreira mecânica, fornecida pela camada paliçádica da testa (Corner 1951); barreira química, devida à suberização das paredes periclinais externas (Quinlivan 1971); barreira química, pela formação de cutícula (White 1908, Rees 1911); barreira química, pela presença de compostos fenólicos nas células da testa (Werker et al. 1973). No caso de T. tipu, observou-se que o pericarpo no núcleo seminífero apresenta cutícula, possui intensa lignificação e grande quantidade de compostos fenólicos, assumindo o papel do tegumento, que é delgado e pouco diferenciado, não exibindo a estrutura típica de leguminosas relatada por Corner (1951, 1976). Tal fato era esperado, sendo a regra para sementes inclusas em pericarpos indeiscentes.

Embora a anatomia do tegumento revele estrutura muito simplificada se comparada ao tegumento típico das leguminosas, a morfologia do hilo avantajado, rodeado pelo nítido rim hilar, evidencia que $T$. tipu apresenta algumas das características mais marcantes das Faboideae (Corner 1951).

Agradecimentos - À Acadêmica Ana Claudia Nóbrega Siqueira, pela indispensável ajuda nas atividades práticas. À FAPESP (processo n⿳⺈ 98/06547-0), pela bolsa de Iniciação Científica de M.A.G.Martins.

\section{Referências bibliográficas}

BARROSO, G.M., MORIM, M.P., PEIXOTO, A.L. \& ICHASO, C.L.F. 1999. Frutos e sementes: morfologia aplicada à sistemática de dicotiledôneas. Editora UFV, Viçosa.

BISSON, C.S. \& JONES, H.A. 1932. Changes accompanying fruit development in the garden pea. Plant Physiology 7:91-105.

BOELCKE, O. 1946. Estudio morfológico de las semillas de Leguminosas Mimosoideas y Cesalpinoideas de interés agronómico en la Argentina. Darwiniana 7:240-321.

BRAVATO, M. 1974. Estudio morfologico de frutos e semillas de las Mimosoideae (Leguminosae) de Venezuela. Acta Botanica Venezuelica 9:317-361.

BURNHAM, R.J. 1995. A new species of winged fruits from the Miocene of Ecuador: Tipuana ecuatoriana (Leguminosae). American Journal of Botany 82:1599-1607.

CORNER, E.J.H. 1951. The leguminous seed. Phytomorphology 1:117-150.

CORNER, E.J.H. 1976. The seeds of dicotyledons. v.1. University Press, Cambridge.

CORNER, E.J.H. 1976. The seeds of dicotyledons. Illustrations. v.2. University Press, Cambridge.

DUDIK, N.M. 1981. Morphology of the pods of Leguminales (Fabales). In Advances in legume systematics. (R.M. Polhill \& P.H. Raven, eds.). Royal Botanical Gardens, Kew, Part 2, p.897-901.

EAMES, A.J. 1977. Morphology of the Angiosperms. Robert E. Krieger, Huntington. 
EAMES, A.J. \& MACDANIELS, L.H. 1953. An introduction to plant anatomy. 3 ed. Tata McGraw-Hill Publishing, New Delhi.

FAHN, A. \& ZOHARY, M. 1955. On the pericarpial structure of the legumen, its evolution and relation to dehiscence. Phytomorphology 5:99-111.

FUCHS, C. 1963. Fuchsin staining with $\mathrm{NaOH}$ clearing for lignified elements of whole plants or plants organs. Stain Technology 38:141-144.

GUNN, C.R. 1984. Fruits and seeds of genera in the subfamily Mimosoideae (Fabaceae). Technical Bulletin 1681:1-194.

JENSEN, W.A. 1962. Botanical histochemistry: principles and practice. W.H. Freeman, San Francisco.

JOHANSEN, D.A. 1940. Plant microtechnique. McGraw-Hill Book Company Inc., New York.

KARNOVSKY, M.J. 1965. A formaldehyde-glutaraldehyde fixative of high osmolality for use in electron microscopy. Journal of Cell Biology 27:137A-138A.

LAKSHMANAN, K.K. \& AMBEGAOKAR, K.B. 1984. Polyembryony. In Embryology of Angiosperms (B.M. Johri, ed.). Springer-Verlag, Berlin, p.445-474.

LILLELAND, O. 1930. Growth study of the apricot fruit. Proceeding of the American Society for Horticultural Science 29:237-245.

LILLELAND, O. 1932. Growth study of the peach fruit. Proceeding of the American Society for Horticultural Science 29:8-12.

LILLELAND, O. 1933. Growth study of the plum fruit - I. The growth and changes in chemical composition of the climax plum. Proceeding of the American Society for Horticultural Science 30:203-208.

LIMA, H.C. 1989-1990. Tribo Dalbergieae (Leguminosae Papilionoideae) - morfologia dos frutos, sementes e plântulas e sua aplicação na sistemática. Arquivos do Jardim Botânico do Rio de Janeiro 30:1-42.

LIMA, M.P.M. 1985. Morfologia dos frutos e sementes dos gêneros da tribo Mimoseae (Leguminosae - Mimosoideae), aplicada à sistemática. Rodriguésia 37:53-78.

NITSCH, J.P. 1953. The physiology of fruit growth. Annual Review of Plant Physiology 4:199-236.

O'BRIEN, T.P., FEDER, N. \& McCULLY, M.E. 1964. Polychromatic staining of plant cell walls by toluidine blue O. Protoplasma 59:368-373.

OLIVEIRA, D.M.T. 1997. Análise morfológica comparativa de frutos, sementes, plântulas e plantas jovens de 30 espécies arbóreas de Fabaceae ocorrentes no Estado de São Paulo. Tese de doutorado, Universidade Estadual Paulista, Rio Claro.

OLIVEIRA, D.M.T. \& BELTRATI, C.M. 1993. Aspectos anatômicos dos frutos e sementes em desenvolvimento de Inga fagifolia (Fabaceae: Mimosoideae). Revista Brasileira de Biologia 53:625-636.

OLIVEIRA, D.M.T. \& BELTRATI, C.M. 1994. Morfologia e anatomia dos frutos e sementes de Inga fagifolia Willd. (Fabaceae: Mimosoideae). Revista Brasileira de Biologia 54:91-100

PAGANO, S.N. \& LEITÃO-FILHO, H.F. 1987. Composição florística do estrato arbóreo de mata mesófila semidecídua, no município de Rio Claro (Estado de São Paulo). Revista Brasileira de Botânica 10:37-47.
POLHILL, R.M. 1981a. Papilionoideae. In Advances in legume systematics. (R.M. Polhill \& P.H. Raven, eds.). Royal Botanical Gardens, Kew, Part 1, p.191-204.

POLHILL, R.M. 1981b. Dalbergieae. In Advances in legume systematics. (R.M. Polhill \& P.H. Raven, eds.). Royal Botanical Gardens, Kew, Part 1, p.233-242.

POLHILL, R.M, RAVEN, P.H. \& STIRTON, C.H. 1981. Evolution and systematics of the Leguminosae. In Advances in legume systematics. (R.M. Polhill \& P.H. Raven, eds.). Royal Botanical Gardens, Kew, Part 1, p.1-26.

QUINLIVAN, B.J. 1971. Seed coat impermeability in legumes. The Journal of the Australian Institute of Agricultural Science 37:283-293

RAVEN, P.H. \& POLHILL, R.M. 1981. Biogeography of the Leguminosae. In Advances in legume systematics. Part 1 (R.M. Polhill \& P.H. Raven, eds.). Royal Botanical Gardens, Kew, p.27-34.

REES, B. 1911. Longevity of seeds and structure and nature of seed coat. Proceedings of the Royal Society of Victoria, New Series 23:393-414.

ROOSMALEN, M.G.M. 1985. Fruits of the guianan flora. Institute of Systematic Botany, Utrecht University, Utrecht.

ROTH, I. 1977. Fruits of angiosperms. Gebrüder Borntraeger, Berlin. (Handbuch der Pflanzenanatomie).

SANCHOTENE, M.C.C. 1985. Frutíferas nativas úteis à fauna na arborização urbana. FEPLAN, Porto Alegre.

SASS, J.E. 1951. Botanical microtechnique. 3 ed. Iowa State University Press, Ames.

SOUZA, L.A. 1984. Anatomia do desenvolvimento do pericarpo de Lonchocarpus muehlbergianus Hassler (Leguminosae Faboideae). Revista UNIMAR 6:5-19.

SPJUT, R.W. 1994. A systematic treatment of fruit types. Memoirs of the New York Botanical Garden 70:1-182.

SUÁREZ, G.R. \& ENGLEMAN, E.M. 1980. Deposito de taninos en la testa de Amaranthus hypochondriacus L. (alegria). Agrociencia 42:35-50.

TUCKEY, H.B. \& YOUNG, J.O. 1939. Histological study of the developing fruit of the sour cherry. Botanical Gazette 100:723-749.

VAN DER PIJL, L. 1982. Principles of dispersal in higher plants. 3 ed. Springer-Verlag, Berlin.

VIDAL, W.N. \& VIDAL, M.R.R. 1992. Botânica - Organografia: quadros sinóticos ilustrados de fanerógamos. 3 ed. Imprensa Universitária, Viçosa.

VILLARI, R. 1990-1991. Embryological observations on Tipuana tipu (Benth.) O. Kuntze (Dalbergieae, Papilionaceae). Giornale Botanico Italiano 124:293-300.

VON TEICHMAN, I. \& VAN WYK, A.E. 1991. Trends in the evolution of dicotyledonous seeds based on character associations, with special reference to pachychalazy and recalcitrance. Botanical Journal of the Linnean Society 105:211-237.

WERKER, E., DAFNI, A. \& NEGBI, M. 1973. Variability in Prosopis farcata in Israel: anatomical features of the seed. Botanical Journal of the Linnean Society 66:223-232.

WHITE, J. 1908. The occurrence of an impermeable cuticle on the exterior of certain seeds. Proceedings of the Royal Society of Victoria 21:203-210. 